\title{
Signet Ring Cell Carcinoma
}

National Cancer Institute

\section{Source}

National Cancer Institute. Signet Ring Cell Carcinoma. NCI Thesaurus. Code C3774.

A usually aggressive, poorly differentiated invasive adenocarcinoma characterized by the presence of malignant glandular cells in which the nucleus is pressed to one side by the presence of intracytoplasmic mucus. It may arise from the stomach, small and large intestine, ampulla of Vater, appendix, gallbladder, pancreas, lung, bladder, breast, and prostate gland. 